\title{
Creación de una máquina picadora y trituradora de especies forrajeras para alimentación de ganado en la provincia de Chimborazo, parroquia Calpi.
}

\section{Creation of a picking and shredding machine to feed species for feeding livestock in the province of Chimborazo, Calpi parish}

Eugenia Mercedes Naranjo Vargas ${ }^{1}$, Carlos José Santillán Mariño ${ }^{2}$, Daniela Belén García Madroñero ${ }^{3}$ \& Rodolfo Efrén Pilco Ruiz ${ }^{4}$

\begin{abstract}
.
DOI: https://doi.org/10.33262/cienciadigital.v9i2.378

The objective of the project was to know the reality that the agricultural producers live in the sector of the parish of Calpi belonging to the province of Chimborazo and also seeks to improve in some way some procedures that are required to prepare and optimize food for livestock. It was observed that the feed for livestock must be constant in addition to containing a high nutritional value in terms of fiber, vitamins, minerals and proteins. Therefore, it is advisable to supply the rations in several balanced portions so that the animal has enough time to make a correct digestion, and an optimal development depending if it is for meat, production of young or for milk. Based on everything said above, in order to improve the methods that were made in a manual way, it is possible to design and implement a crushing machine for forage products. This machine aims to reduce costs in the feeding of livestock and fundamentally to prepare in a personal, fast and balanced way the food that the cattle

\footnotetext{
${ }^{1}$ Escuela Superior Politécnica de Chimborazo, Facultad de Mecánica, Carrera de Ingeniería Industrial. Riobamba, Ecuador, eugenia.naranjo@espoch.edu.ec

2 Escuela Superior Politécnica de Chimborazo, Facultad de Mecánica, Carrera de Ingeniería Industrial. Riobamba, Ecuador, carlos.santillan@espoch.edu.ec

${ }^{3}$ Escuela Superior Politécnica de Chimborazo, Facultad de Mecánica, Carrera de Ingeniería Industrial. Riobamba, Ecuador, daniela_bgm2017@hotmail.com

${ }^{4}$ Escuela Superior Politécnica de Chimborazo, Facultad de Mecánica, Carrera de Ingeniería Industrial. Riobamba, Ecuador, prodolfopilco29@gmail.com
} 
require. Producers will have a better way to crush and chop forage species, as well as different types of tubers. Thanks to this, it is possible to save storage spaces for livestock feed, with the peculiarity of being able to take better control of the nutrients needed in the daily feeding of each animal according to the species and size of the livestock.

Keywords: crushing machine, forage species, chopped, cattle.

\section{Resumen.}

El objetivo del proyecto fue conocer la realidad que viven los productores agrícolas en el sector de la parroquia de Calpi perteneciente a la provincia de Chimborazo y también se busca mejorar de alguna forma algunos procedimientos que se requieren para preparar y optimizar el alimento para el ganado. Se pudo observar que el alimento para el ganado debe ser constante además de contener un alto valor nutricional en cuanto a fibra, vitaminas, minerales y proteínas. Por tanto, es recomendable suministrar las raciones en varias porciones equilibradas para que el animal tenga el tiempo suficiente para realizar una correcta digestión, y un óptimo desarrollo dependiendo si es para carne, producción de crías o para leche.

En base a todo lo dicho anteriormente, con la finalidad de mejorar los métodos que se hacían de una forma manual, se logra diseñar e implementar una máquina trituradora para productos forrajeros. Ésta máquina pretende disminuir costos en la alimentación del ganado y fundamentalmente preparar de manera personal, rápida y equilibrada los alimentos que requiere el ganado. Los productores tendrán una mejor forma de triturar y picar especies forrajeras, así como diferentes tipos de tubérculos. Gracias a esto se puede economizar los espacios de almacenamiento del alimento para el ganado, con la particularidad de poder llevar un control más adecuado de los nutrientes necesarios en la alimentación diaria de cada animal de acuerdo a la especie y tamaño del ganado.

Palabras claves: máquina trituradora, especies forrajeras, picado, ganado.

\section{Introducción.}

Actualmente en el país, gracias a la riqueza de terreno y a la flora que posee, muchas de las organizaciones tanto gubernamentales como del sector privado están enfocadas en gran medida a impulsar el sector agrícola, aportando de esta forma con el desarrollo económico del Ecuador.

Con el pasar de los años, y debido a la demanda de productos agrícolas, la tecnología, conjuntamente con la modernización de herramientas han permitido a la comunidad campesina, innovar e implementar nuevos métodos de sembrado y cosecha de sus terrenos. 
Todo esto con el fin de facilitar la vida diaria del productor, y también producir más y en menor tiempo. Es por ello que se propone el desarrollo de una máquina trituradora para productos forrajeros.

El diseño, desarrollo e implementación de dicha máquina está dirigido para la parroquia Calpi ubicada en la Provincia de Chimborazo. Con ella, los productores tendrán un mayor control sobre los alimentos que consume el ganado, con esto se aprovechará por completo todo el alimento evitando el desperdicio excesivo que se tiene cuando el ganado se le alimenta con productos forrajeros enteros. Al implementar dicha maquinaría también se podría reducir el tiempo que se dedica a la alimentación del ganado, la mano de obra, optimizar el alimento para el ganado, así como otros aspectos importantes que interviene en la vida diaria del campesino.

\section{Picadora de Forrajes}

La picadora de forrajes es una máquina que se usa convertir en pequeñas partículas diferentes tipos de plantas que usualmente se destinan a la alimentación del ganado, en este caso en su gran parte existen varias especies forrajeras. Las diferentes especies de flora por lo general se suministran enteras a la máquina. Todo el producto procesado es lanzado por un tubo de descarga (contributors, Picadora de forrajes, 2012).

Figura 1: Máquinas Trituradora.

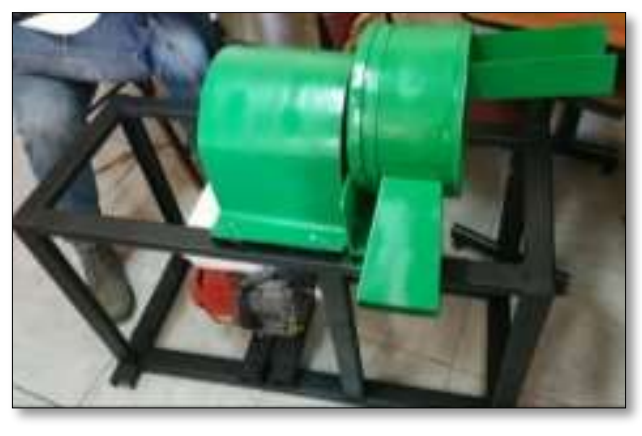

Fuente: Los autores.

\section{Funcionamiento}

El funcionamiento teórico de la máquina trituradora se basa en el accionamiento de un motor eléctrico o a su vez puede ser de combustión interna, puede funcionar a base de gasolina o diésel, lo más común que se puede encontrar en el país. Toda máquina picadora se compone de una estructura metálica, en el centro tiene un eje que es movido por el motor, este eje se compone de cuchillas que van cortando todas las plantas que se ingresen a la máquina. También en algunos casos, tiene un ventilador interno que las lanza las partículas picadas al exterior a través de un tubo de descarga. (contributors, Picadora de forrajes, 2012) 


\section{Componentes}

Bastidor: Estructura metálica que sirve de soporte para todos los elementos que conforman la máquina, entre ellos el motor, polea, rotor, las carcasas protectoras, la bandeja de alimentación y el tubo de descarga.

Figura 2: Diseño Bastidor.

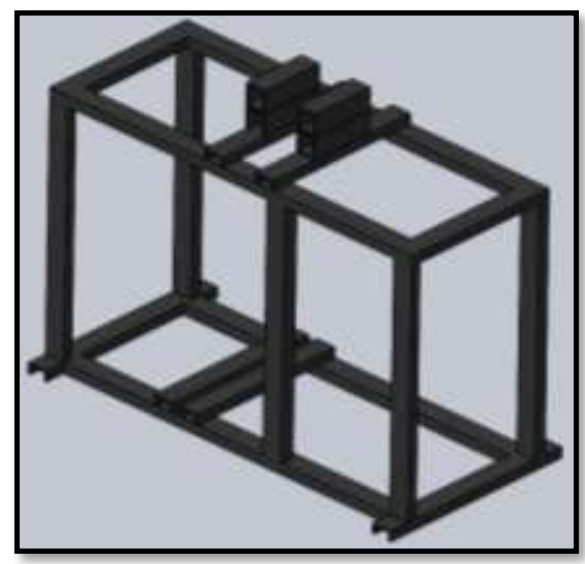

Fuente: Los autores.

Bandeja de alimentación: Generalmente son formadas por planchas de acero, se sitúa en la entrada de la máquina y se dirige hacia el rotor, se coloca a una altura determinando para la comodidad del obrero. Todo el material se inserta sobre la bandeja de alimentación y posteriormente se empuja poco a poco mientras se va picando el alimento por las cuchillas. (contributors, Picadora de forrajes, 2012).

Figura 3: Diseño bandeja de alimentación.

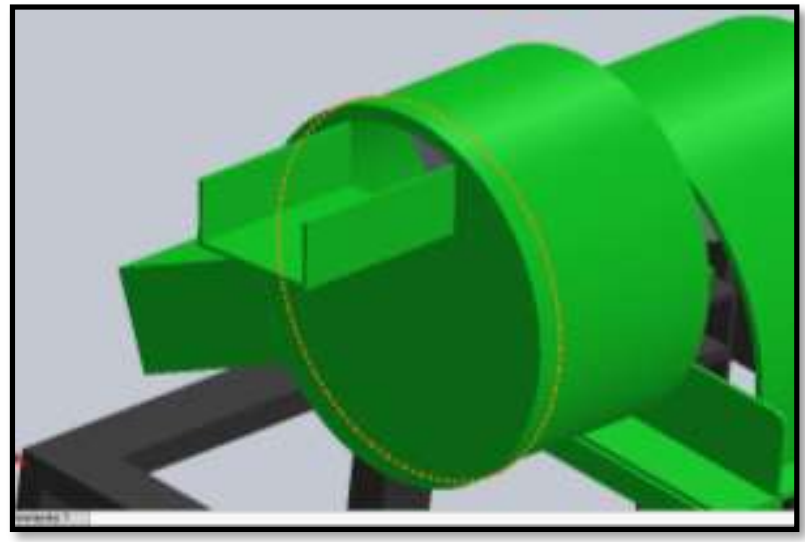

Fuente: Los autores

Fuente energética: Por lo general para dar movimiento a toda máquina se usa un motor con el fin de trasmitir la rotación a una polea, que a su vez mueve a la polea del rotor a través de 
correas, con esto se consigue dar movimiento a las cuchillas para picar el alimento, para lo cual se seleccionó un motor de combustión a gasolina de segunda mano.

Figura 4: Diseño motor

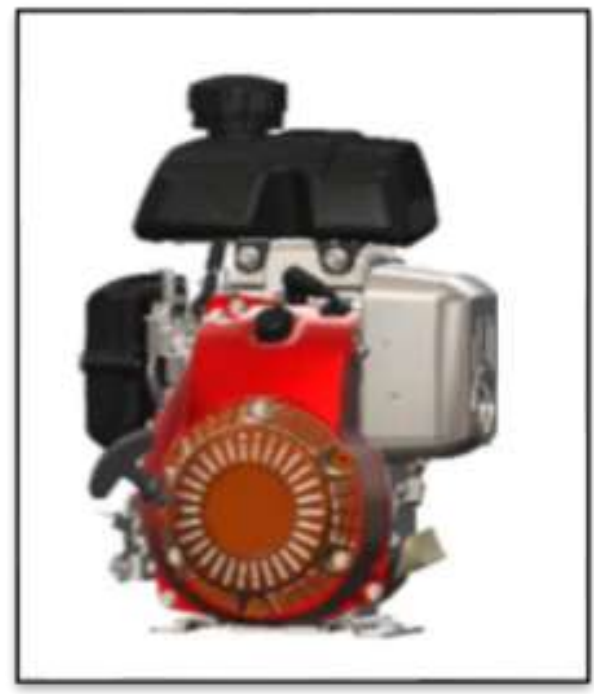

Fuente: Biblioteca solidworks

Carcazas protectoras: Son piezas constituidas por láminas de metal que protegen al operador debido al peligro que existe por los componentes en movimiento, ya sean poleas, correas, rotor, etc.

Figura 5: Diseño carcaza

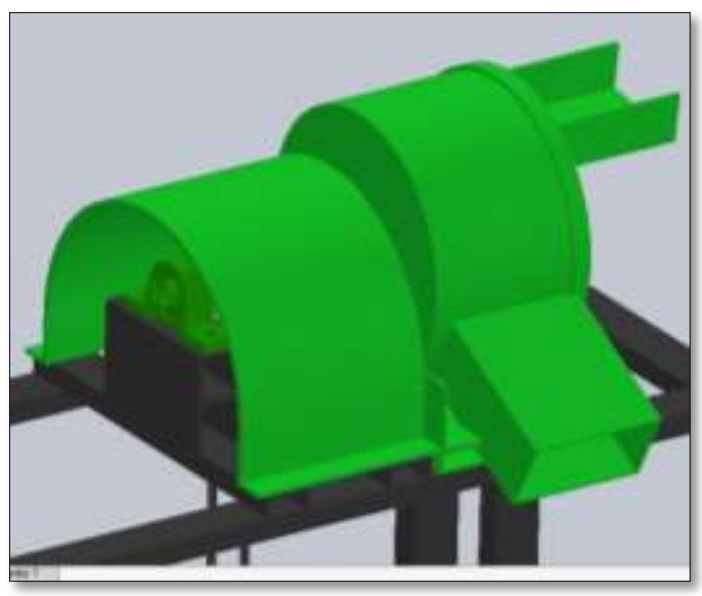

Fuente: Los autores

Cuchillas: El eje de la máquina, es decir el rotor posee de dos a cuatro cuchillas que al girar van cortando en pequeñas partículas el material que se inserte en la máquina. 
Figura 6: Diseño cuchilla

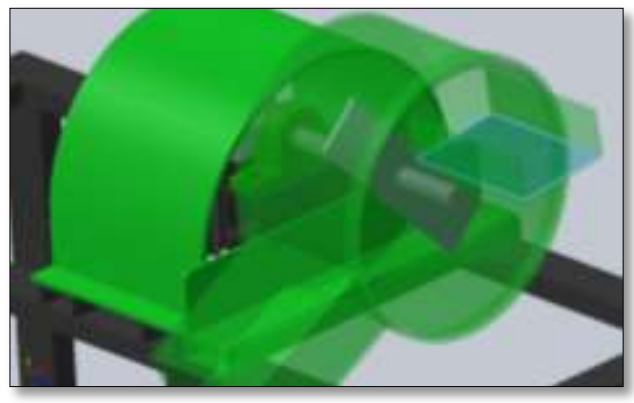

Fuente: Los autores

Tubo de descarga: Pieza que tiene la forma de un tubo, el cual se caracteriza porque es de sección cuadrada. Desde esta componente permite desplazar las plantas picadas hacia el exterior. Dependiendo de la altura, permite la entrega directa a un medio de transporte o la descarga formando pilas de almacenamiento (contributors, Picadora de forrajes, 2012).

Figura 7: Diseño tubería de descarga

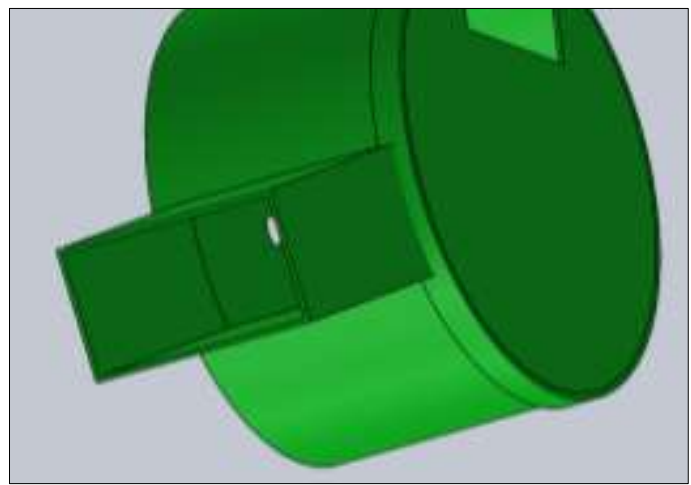

Fuente: Los autores

Figura 8: Diseño Máquina Trituradora Forrajera

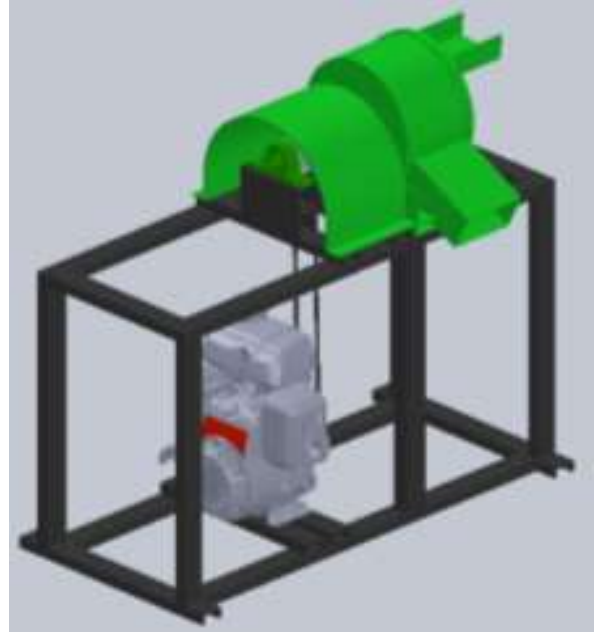

Fuente: Los autores 


\section{Características del Alimento}

Todo el alimento que se debe dar al ganado, para un buen procedimiento de cría, debe ser equilibrado en cuanto a vitaminas, minerales y proteínas se trata, tomando en cuenta los requerimientos de cada animal ya sea edad, sexo o esté destinado a la producción. Por lo general las vacas consumen diariamente cerca del $10 \%$ de pasto fresco con relación a su peso vivo. Por ejemplo, si una vaca pesa $500 \mathrm{~kg}$, entonces en consecuencia debería comer lo siguiente: (Comunicación, 2017)

$500 \mathrm{~kg}$ de peso vaca $\times 10 \%=50 \mathrm{~kg}$ de pasto fresco/día

Las haciendas ganaderas pueden dedicarse al negocio de carne, leche o sus derivados, es por ello que involucra distintas etapas desde que el ternero nace hasta que está listo para la comercialización del producto final, así que el tema de alimentación y nutrición del ganado es esencial, además es muy importante para obtener buenos ingresos monetarios. (Fonseca, 2016)

La ración diaria que se destina para la alimentación debe proveer de una adecuada cantidad de nutrientes para el crecimiento, mantenimiento corporal y preñez. Los alimentos deben contener carbohidratos, proteína, minerales, vitaminas, agua y la cantidad necesario de alimento apropiado y balanceado.

Sabiendo todo esto, a continuación, se detalla el proceso que tiene que hacer el ganadero para alimentar a sus animales con la ayuda de la máquina trituradora propuesta en el presente proyecto.

Figura 9: Etapas para la alimentación del ganado

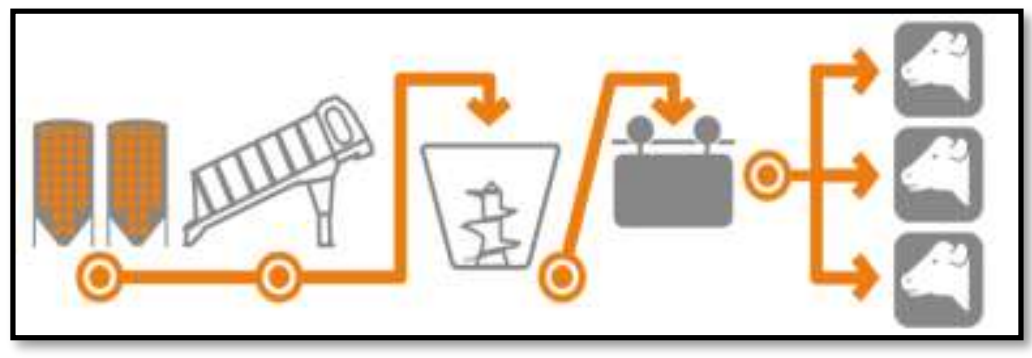

Fuente: https://www.gea.com.es

Todo el alimento destinado al ganado bovino debe ser fresco, también se debe variar de acuerdo a valores nutricionales de flora y entregar de acuerdo a la edad del animal. Todo el alimento que se obtiene de las cosechas, debe estar previamente clasificado y balanceado en contenedores especiales con condiciones de luz y temperatura adecuadas.

El ganadero debe extraer la cantidad necesaria que se le dará al ganado en el día desde los contenedores. Una vez elegida la cantidad debe colocar el alimento forrajero en la bandeja 
de entrada de la máquina. Una vez hecho esto, el producto caerá progresivamente por la tubería que conduce hacia la cámara trituradora donde se encuentra las cuchillas. En cuanto a las cuchillas su tamaño grosor y otras características dependerán directamente del tipo de alimento final que tendrá o que requiera el productor para su ganado.

Después de esto, en la sección de picado, las cuchillas inician su movimiento y van girando dependiendo a las revoluciones dadas por un elemento de potencia como es el motor. Se consigue de esta forma que el alimento vaya siendo triturado progresivamente, este alimento ya triturado cae sobre una tubería final donde mediante un ventilador adicional el producto es lanzado al exterior desde la bandeja final hacia un contenedor esperando el alimento picado.

Para finalizar este proceso se procede a guardar los alimentos o a su vez, se los utiliza inmediatamente para la alimentación del ganado bovino. La máquina adicionalmente tiene un acceso o compuerta hacia el contenedor de las cuchillas donde se alojarán los desperdicios, los cuales serán desalojados por dicho acceso. Adicional, se lo puede utilizar para el mantenimiento de la máquina tanto en la parte mecánica de movimiento, así como en la sección de picado que constituyen las cuchillas y otros elementos cortantes.

\section{Metodología.}

En el proceso de análisis tanto de diseño, como de construcción se aplica metodología empírico descriptivo aplicativo al desarrollo de la presente máquina además de detallar un proceso de desarrollo en el que se detalla a continuación.

Figura 9: Diagrama de flujo de la creación de la máquina trituradora

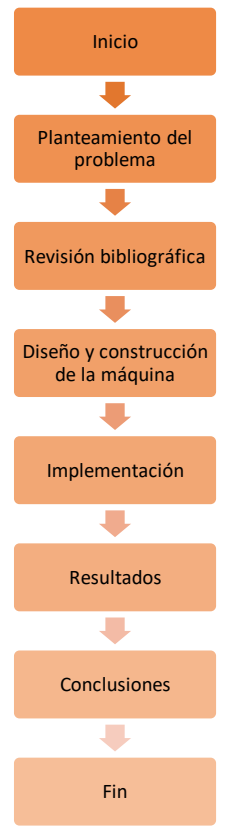

Fuente: Los autores 


\section{Resultados.}

\section{Parámetros de Diseño}

\section{Volumen de la Tolva}

La tolva de alimentación es el cuerpo que permite la entrada del producto hacia la cámara de trituración, entonces el ganadero debe calcular la cantidad de ganado que tiene, en este caso se debe alimentar a un promedio de 30 cabezas de ganado de distintas edades por día.

La capacidad de producción de alimento por día debe ser en un promedio de 1.5 toneladas. El recinto donde tienen al ganado tiene la posibilidad de aumentar más animales, así que para el diseño de la máquina se ha considerado el doble de la capacidad de producción diaria actual.

El tiempo que va a trabajar la máquina es de 8 horas diarias, entonces la capacidad de producción deberá ser calculada de la siguiente manera:

$$
Q=\frac{Q_{d}}{H}
$$

\section{Donde:}

$\mathbf{Q}=$ capacidad real por hora.

$\mathbf{Q}_{\mathbf{d}}=$ capacidad real de trabajo.

$\mathbf{H}=$ número de horas de trabajo por día.

Y aplicando la Ecuación 1 con datos numéricos se tiene:

$$
Q=\frac{1.5 \frac{\text { ton }}{\text { día }}}{8 \frac{\text { horas }}{\text { día }}}=0.1875 \frac{\text { ton }}{\text { hora }}
$$

Como existe la posibilidad de duplicar la producción entonces se tiene:

$$
Q=0,375 \frac{\text { ton }}{\text { hora }}
$$

Por consiguiente, para soportar todo ese volumen de producto para la trituración, las medidas de la tolva que se va a usar son:

Área Base inferior $=0.0216 \mathrm{~m}^{2}$

- Ancho $=0.18 \mathrm{~m}$

- Alto $=0.12 \mathrm{~m}$ 
Área Base superior: $0.048 \mathrm{~m}^{2}$

- Ancho $=0.4 \mathrm{~m}$

- Alto $=0.12 \mathrm{~m}$

Altura entre bases: $700 \mathrm{~mm}$

Entonces para calcular el volumen que va a soportar la tolva diseñada se aplica la siguiente fórmula:

$$
\begin{gathered}
V=\frac{h}{3} *(A 1 * A 2+\sqrt{A 1 * A 2}) \\
V=7755,11 \mathrm{~mm}^{3}
\end{gathered}
$$

\section{Sistema de transmisión mecánica}

Para el proceso de movimiento de las cuchillas de corte forman parte fundamental del diseño del sistema mecánico, se lo realizó mediante el principio de transmisión mecánica, es decir un conjunto de dos poleas ubicadas de tal manera una cierta distancia y un ángulo de inclinación, acopladas por medio de una correa por efecto del rozamiento, se transmita potencia desde un punto a otro, esta fuerza se transmite por el giro del motor sobre la polea ubicado en un extremo, ejerciendo un movimiento sobre la correa y finalmente transmitiendo la potencia generada sobre la polea del otro extremo.

\section{Componentes del sistema de transmisión}

- Polea motriz: también llamada polea conductora, esta polea está sujeta al eje del motor, el mismo que permite el movimiento a la correa adquiriendo de esta manera un movimiento propio. (aprendemostecnologia.org, 2015)

- Polea conducida: esta polea es la que se encuentra anclada un eje al que se desea generar el movimiento, en este caso al rotor de las cuchillas

- Correa de transmisión: son cintas cerradas de cuero flexible y otros materiales resistentes que se emplea para transmitir el movimiento de rotación entre los dos ejes.

\section{Calculo de la longitud de la correa de transmisión}

Para saber que la longitud de la correa que se ajustará entre las dos poleas se aplica la fórmula:

$$
L=\frac{\pi}{2}(D+d)+2 C+\frac{(D-d)^{2}}{4 C}
$$




\section{Donde:}

$\mathbf{L}=$ Longitud de la correa en $\mathrm{mm}$.

D = Diámetro de la polea mayor.

$\mathbf{d}=$ Diámetro de la polea menor.

$\mathbf{C}=$ Distancia entre centros.

Entonces, con los datos conocidos se procede a obtener el dato numérico de la longitud de la correa. Se toma en cuenta el uso de un par de poleas de diferente diámetro.

\section{Datos:}

$\mathbf{D}=60 \mathrm{~mm}, \mathbf{d}=35 \mathrm{~mm}, \mathbf{C}=480 \mathrm{~mm}$

Aplicando la ecuación 5 se obtiene:

$$
\begin{gathered}
\boldsymbol{L}=\frac{\pi}{2}(60 \mathrm{~mm}+35 \mathrm{~mm})+2(480 \mathrm{~mm})+\frac{(60 \mathrm{~mm}-35 \mathrm{~mm})^{2}}{4(480 \mathrm{~cm})} \\
\boldsymbol{L}=\mathbf{1 1 0 9 . 8 6} \mathbf{~ m m}
\end{gathered}
$$

\section{Cálculo de torque de un motor}

Para el cálculo del torque que proporciona usamos la siguiente formula.

$$
T=\frac{H P * 716}{r p m}\left(\mathrm{Kg}_{-\mathrm{m})}\right.
$$

$$
\begin{aligned}
& T=\frac{H P * 716}{r p m}\left(\mathrm{Kg}_{-\mathrm{m})}\right. \\
& T=\frac{5.5 \cdot 716}{3.500}\left(\mathrm{Kg}_{-\mathrm{m})}\right. \\
& \mathrm{T}=1,12(\mathrm{Kg}-\mathrm{m})
\end{aligned}
$$


Figura 11: Cálculo de torque de un motor

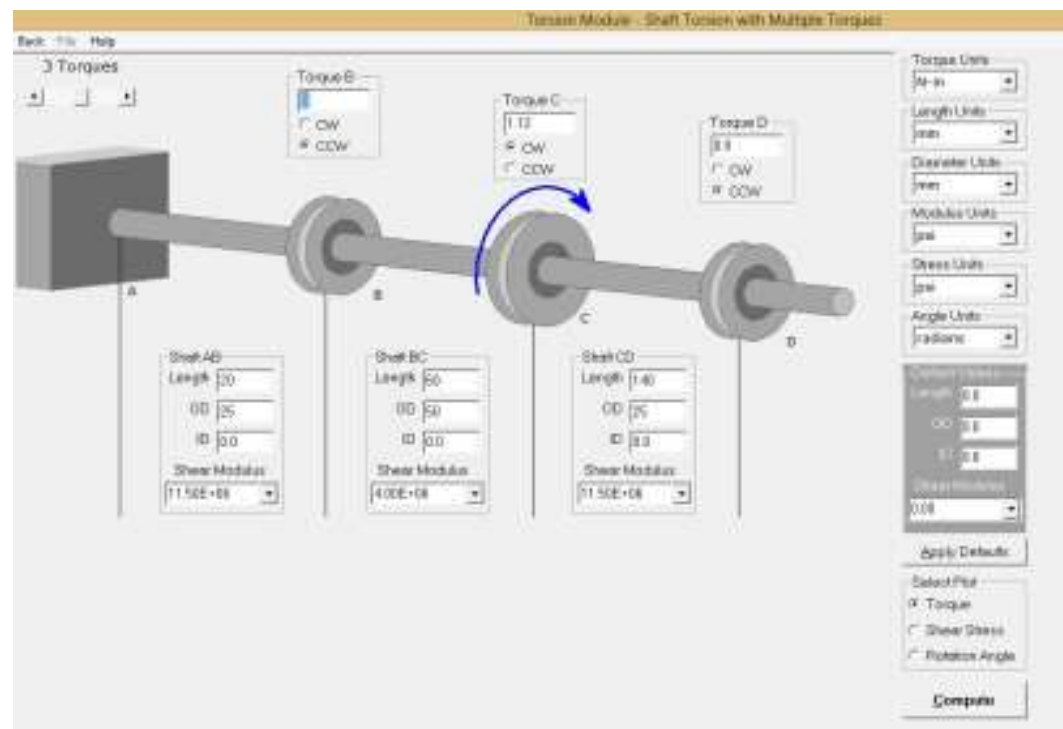

Fuente: Los autores

Esfuerzo de Torsión

$$
\tau_{z y}=\frac{T \gamma}{J}=\frac{16 T}{\pi d^{3}}
$$

Para ejes macizos

$$
\begin{aligned}
& T=\frac{16(17,57)}{\Pi(1)^{: 3}} \\
& T=84,43 \frac{L b}{b n^{2}}
\end{aligned}
$$

\section{Esfuerzo de Flexión}

$$
\sigma_{x}=\frac{M}{I}=\frac{32 M}{\pi d^{3}}
$$

Para ejes macizos

$$
\begin{aligned}
& \gamma_{X}=\frac{32(27,57)}{\Pi(1)^{3}} \\
& T_{X}=280,82 \frac{L b}{\mathrm{Ln}^{2}}
\end{aligned}
$$


Esfuerzo de Axiales

$$
\sigma \mathrm{e}=4 F / \pi d
$$

Para ejes macizos

$$
\begin{aligned}
T_{X} & =\frac{4(33.07)}{\Pi(1)^{2}} \\
T_{X} & =42,10 \frac{L b}{i n^{2}}
\end{aligned}
$$

Al hacer las pruebas pertinentes con la máquina, se detectaron posibles fallas y por ende se presentan posibles soluciones para un mejor uso de la máquina construida.

\section{Problemas}

1. Baja producción

2. La máquina no puede moler productos secos

3. El motor no enciende fácilmente

4. Acumulación de producto dentro de la máquina

5. Corte irregular del producto

\section{Posibles causas del problema}

1. Para la baja producción se puede tener: El producto introducido está húmedo, no existe suficiente producto en la tolva

2. Puede que exista un elemento o residuos en grandes cantidades que bloqueen el movimiento normal del eje o a su vez están demasiados gastados

3. La causa se debe a que se está excediendo al momento de insertar el producto que la máquina pueda soportar y por eso el motor no puede arrancar fácilmente

4. Al tener demasiado alimento a triturar no permite el giro normal del motor

5. Se puede deber a falta de filo en las cuchillas

\section{Soluciones}

1. Se debe insertar solamente productos secos

2. Limpiar la máquina una vez terminada la jornada laboral

3. Antes de encender verificar que la cámara de trituración esté vacía

4. Apagar brevemente la máquina y limpiar los excesos de producto

5. Se debe afilar nuevamente las cuchillas. 


\section{Conclusiones.}

- Dentro del estudio dinámico se pudo comprender profundamente varias leyes que rigen al movimiento del rotor para mover las cuchillas conjuntamente con el sistema de transmisión mecánica, verificando de esta forma las leyes físicas que lo rigen.

- Se pudo aplicar ecuaciones para obtener los cálculos necesarios que permitan dimensionar los diferentes mecanismo y componentes que actúan en la máquina trituradora para que cumpla de manera correcta la función asignada.

- Se concluye que la máquina puede trabajar eficazmente al picar diferentes plantas y productos forrajeros siempre y cuando se respete la capacidad permitida de materia prima.

- La máquina cumple con el objetivo propuesto, logrando así optimizar el tiempo de los trabajadores, además se puede mezclar el alimento destinado al ganado para variar los nutrientes necesarios para la crianza del animal de acuerdo a la edad en la que se encuentre.

\section{Referencias bibliográficas.}

Aldana, S., Vereda, F., Hidalgo-Alvarez, R., \& de Vicente, J. (2016). Facile synthesis of magnetic agarose microfibers by directed selfassembly. Polymer, 93, 61-64.

Bhat, S., Tripathi, A., \& Kumar, A. (2010). Supermacroprous chitosan-agarose-gelatin cryogels. in vitro characterization and in vivo assesment for cartilage tissue engineering. Journal of the Royal Society Interface, 1-15.

Bossis, G., Marins, J., Kuzhir, P., Volkova, O., \& Zubarev, A. (2015). Functionalized microfibers for field-responsive materials and biological applications. Journal of Intelligent Material Systems and Structures, 1-9.

Cortés, J., Puig, J., Morales , J., \& Mendizábal, E. (2011). Hidrogeles nanoestructurados termosensibles sintetizados mediante polimerización en microemulsión inversa. Revista Mexicana de Ingeniería Química., 10(3), 513-520.

Dias, A., Hussain, A., Marcos, A., \& Roque, A. (2011). A biotechnological perspective on the application of iron oxide magnetic colloids modified with polysaccharides. Biotechnology Advances 29, 29, 142-155.

Estrada Guerrero, R., Lemus Torres, D., Mendoza Anaya, D., \& Rodriguez Lugo, V. (2010). Hidrogeles poliméricos potencialmente aplicables en Agricultura. Revista Iberoamericana de Polímeros, 12(2), 76-87. 
García-Cerda, L., Rodríguez-Fernández, O., Betancourt-Galindo, R., Saldívar-Guerrero, R., \& Torres-Torres, M. (2003). Síntesis y propiedades de ferrofluidos de magnetita. Superficies y Vacío., 16(1), 28-31.

Ilg, P. (2013). Stimuli-responsive hydrogels cross-linked by magnetic nanoparticles. Soft Matter, 9, 3465-3468.

Lewitus, D., Branch, J., Smith, K., Callegari, G., Kohn, J., \& Neimark, A. (2011). Biohybrid carbon nanotube/agarose fibers for neural tissue engineering. Advanced Functional Materials, 21, 2624-2632.

Lin, Y.-S., Huang, K.-S., Yang, C.-H., Wang, C.-Y., Yang, Y.-S., Hsu, H.-C., . . Tsai, C.W. (2012). Microfluidic synthesis of microfibers for magnetic-responsive controlled drug release and cell culture. PLOS ONE, 7(3), 1-8.

Ruiz Estrada, G. (2004). Desarrollo de un Sistema de liberación de fármacos basado en nanopartículas magnéticas recubiertas con Polietilénglicol para el tratamiento de diferentes enfermedades. Madrid: Universidad Autónoma de Madrid. Departamento de Física Aplicada.

Song, J., King, S., Yoon, S., Cho, D., \& Jeong, Y. (2014). Enhanced spinnability of narbon nanotube fibers by surfactant addition. Fiberes and Polymers, 15(4), 762-766.

Tartaj, P., Morales, M., González-Carreño, T., Veintemillas-Verdaguer, S., \& Serna, C. (2005). Advances in magnetic nanoparticles for biotechnology applications. Journal of Magnetism and Magnetic Materials, 290, 28-34.

Wulff-Pérez, M., Martín-Rodriguez, A., Gálvez-Ruiz, M., \& de Vicente, J. ( 2013 ). The effect of polymer surfactant on the rheological properties of nanoemulsions. Colloid and Polymer Science, 291, 709-716.

Zamora Mora, V., Soares, P., Echeverria, C., Hernández , R., \& Mijangos, C. (2015). Composite chitosan/Agarose ferrogels for potential applications in magnetic hyperethermia. Gels., 1, 69-80.

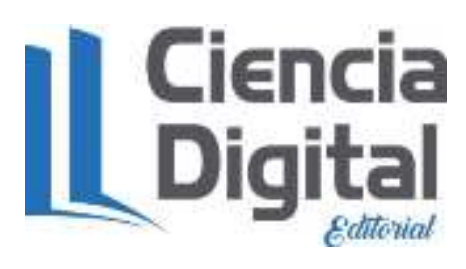




\section{Para citar el artículo indexado.}

Naranjo E., Santillán C., García D., \& Pilco R. (2019). Creación de una máquina picadora y trituradora de especies forrajeras para alimentación de ganado en la provincia de Chimborazo, parroquia Calpi. Revista electrónica Ciencia Digital 3(2), 109-123. Recuperado desde:

http://cienciadigital.org/revistacienciadigital2/index.php/CienciaDigital/article/view/378/824

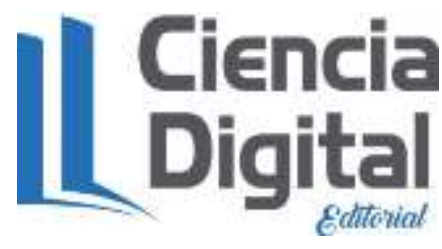

El artículo queda en propiedad de la revista y, por tanto, su publicación parcial y/o total en otro medio tiene que ser autorizado por el director de la Revista Ciencia Digital.
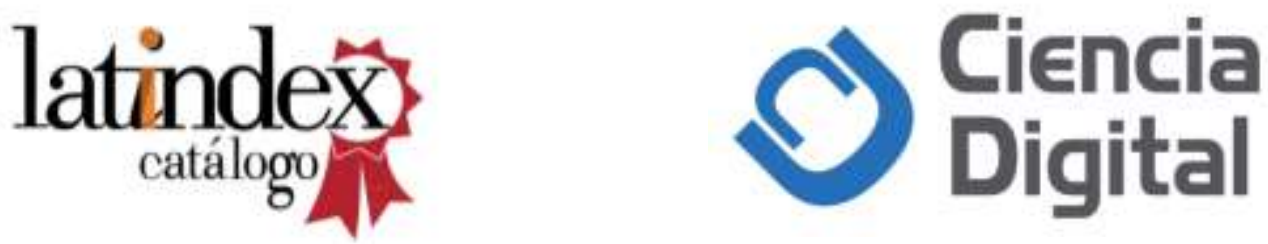